\section{Keeping bloody relics liquid}

SIR - L. Garlaschelli et al. (Nature 353, 507; 1991) suggest an ingenious explanation for the periodic liquefaction of relics of saintly clotted blood. Their thixotropic mixture containing iron and calcium ions in solution would also provide an effective means for maintaining iron in the haem molecule at alkaline $\mathrm{pH}$, particularly useful where the globin component had been long degraded (miraculous preservation excepting). But an even simpler recipe to ensure liquefaction would be to mix a little of the holy man's blood in one of the thixotropic honeys, of which heather (Calluna vulgaris (L.) Hull) would be one widespread and long-known example to be followed on appropriate occasions by a judicious, if not deific, shake in camera.

GEORGE A. F. HENDRY Department of Animal and

ANTHONY J. E. LYON Plant Sciences,

The University, Sheffield S10 2TN, UK

SIR - Does the thixotropic mixture manufactured by L. Garlaschelli et al. (Nature 353, 507; 1991) meet all three criteria for the 'miracle'? First, frothing occurs following liquefaction; second, liquefaction takes up to 30 minutes and frequently longer to occur; and third, liquefaction occurs without the necessity of either tilting the container or turning it upside down. During the religious ceremony described by Garlaschelli et al., the 'blood' is expected to liquefy, then 'boil' and become a frothy liquid. This procedure usually occurs after 40 minutes of fervent praying by a packed congregation. Should the liquefaction be sluggish, there is a great wailing of imprecations and even more fervent praying. Reputedly in the years when liquefaction has not occurred, there have been catastrophes - 1527, plague with more than 40,000 deaths; 1836 , cholera with 24,000 deaths; 1980 , an earthquake with more than 3,000 deaths.

An alternative explanation for the "liquefaction' is that the reliquaries contain a mixture of spermaceti, ether and red dye from roots of the plant alkanet. This mixture is solid at $50^{\circ} \mathrm{F}\left(10^{\circ} \mathrm{C}\right)$, melts when held in the hand from body heat and, if any ether is present, froths and boils. The red dye that is released when roots of alkanet are crushed was used by the Romans to dye wool. Other compounds have been postulated in the past, most suggestions being a mixture of waxes and a red dye, but they failed to meet all three criteria.

JAMES M. DUNLOP

Hull Health Authority, Victoria House,

Park Street, Hull HU2 8TD, UK
The second observation is not particularly surprising and it is difficult to see why Shapiro made so much of it. DNA profiling is so highly discriminating that in the event of a match the accuracy with which one estimates the population frequency is of minor importance. In our laboratory we have demonstrated, in experiments which have been reported at several international meetings and in the literature ${ }^{3}$, that even when we use deliberately distorted or unrepresentative databases the consequences within a forensic context are almost trivial.

Shapiro's points one to four are specious and will create unnecessary fears in the forensic science community, as our own experiments have shown. If I have any criticism of the methods of the FBI it is that its forensic scientists are unnecessarily cautious in the estimates of evidential strength that they derive from their frequency tables.

IAN W. EVETT

psychophysics may not be as rapid or revolutionary as those in molecular genetics, the field has made progress in the refinement of measurement techniques. Quite frankly, I have never asked a patient to eat soap, nor am I aware of 'soap-eating' being advocated as a test for anosmia by anyone currently working in the area of clinical disorders of smell. There are, however, evaluative procedures that enable us to characterize both the nature and degree of chemosensory dysfunctions ${ }^{2-4}$.

BEVERIY J. COWART

Department of Otolaryngology,

Monell-Jefferson Taste and Smell Center,

909 Walnut Street, Philadelphia, Pennsylvania 19107, USA

1. Goodfellow, P. N. \& Sefton, L. Nature 353, 117-118 (1991)

2. Cain, W. S. et al. Laryngoscope 98, $83-88$ (1988)

3. Cowart, B. J. Ann. N.Y. Acad. Sci. 561, 39-55 (1989)

4. Deems, D. A. et al. Arch. Otolaryngol. Head Neck Surg. 117, 519-528 (1991).

\section{Trivial error}

SIR - Shapiro demonstrates ${ }^{1}$, from data collected on DNA profiles at the FBI laboratory, that band-weight measurement errors within the same profile are correlated; and there are systematic differences between the operators who made the measurements.

It is difficult to understand why Shapiro should have been surprised by a correlation phenomenon that has been well documented elsewhere. In 1989, I and colleagues ${ }^{2}$ said that ". . . errors in band positions within a DNA profile are highly correlated ....". P. Gill and I have shown how measurement-error correlations can be built into highly effective statistical procedures ${ }^{3,4}$. We used a correlation coefficient of 0.9 - higher than all but one of those reported by Shapiro.
The Forensic Science Service,

Central Research and Support

Establishment,

Aldermaston, Reading,

Berkshire RG7 4PN, UK

1. Shapiro, M.M. Nature 353, 121-122 (1991)

2. Evett, I.W. et al. Nature 340, 435 (1989).

3. Evett, I.W. \& Gill, P. Electrophoresis 12, 226-230 (1991)

4. Evett, I.W. et al. Int. Symp. Hum. Identification 1989 77-101 (Promega, Maddison, Wisconsin, 1990).

\section{Neutral mutation hypothesis test}

SIR - McDonald and Kreitman ${ }^{1}$ claim that adaptive mutations are largely responsible for the evolution of alcohol dehydrogenase (Adh) because, according to their calculations, in the Adh gene the ratio of nonsynonymous to synonymous substitutions between three Drosophila species $(7: 17)$ is much larger than the ratio $(2: 42)$ within species. However, their test has at least the following problems.

First, McDonald and Kreitman neglect the between-species variation at a nucleotide site, if that site is polymorphic in any of the three species. Both this counting rule and the one we discuss below tend to underestimate between-species variation. For example, at position 1,590 all the alleles in $D$. melanogaster have $\mathrm{T}$, half the alleles in $D$. simulans have $T$ and the other half have $\mathrm{C}$, and all the alleles in D. yakuba have C. At this position, they assigned a single polymorphic synonymous substitution within $D$. simulans but no substitution between species. However, under their assumption of monomorphism in the ancestral species, an additional synonymous substitution must have occurred between $D$. melanogaster and D. yakuba.

Second, they fail to consider the fact NATURE · VOL $354 \cdot 14$ NOVEMBER 1991 